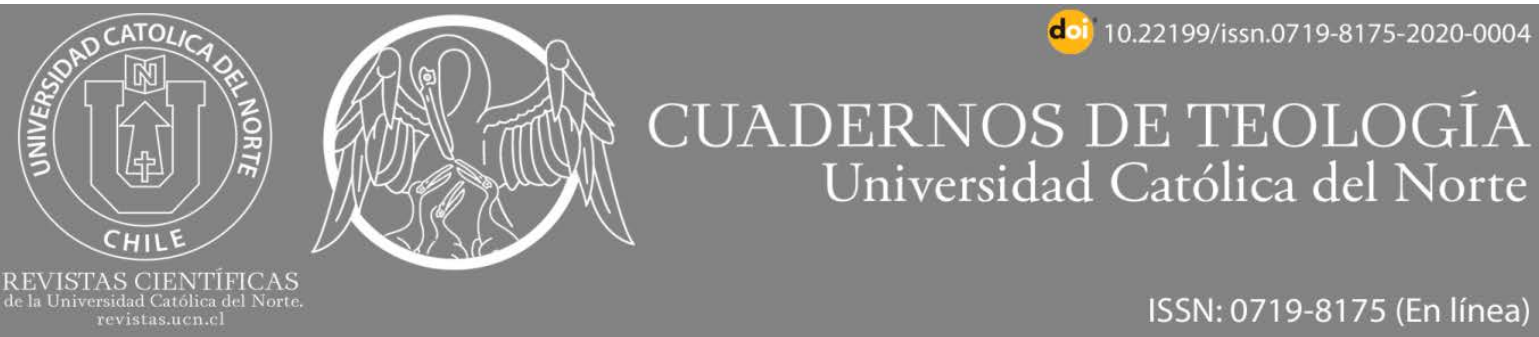

\title{
Teorías subjetivas de profesores de la Región de Coquimbo (Chile) sobre educación espiritual como parte de una educación integral
}

\section{Subjectives theories from Coquimbo Region (Chile) teachers about spiritual education as part of an integral education}

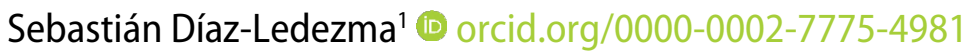 \\ Santiago Gómez-Loyola² $\mathbb{0}$ orcid.org/0000-0002-2353-6583 \\ ${ }^{1}$ Colegio Santo Domingo, La Serena, Chile. Profesor de Filosofía y religión. Magíster en Educación Inclusiva. U. \\ Central de Chile. \\ sdiazl@live.cl \\ ${ }^{2}$ Saint John's School, La Serena, Chile. Orientador. Magíster en Educación Inclusiva. U. Central de Chile. \\ @gomezloyola@gmail.com \\ (cc) BY
}

\section{Resumen:}

Mediante los recursos que ofrece la metodología cualitativa, basados en elementos de la teoría fundamentada, se estudió a profesores de enseñanza básica y media que imparten diversas asignaturas. Los resultados dan cuenta de la elaboración de teorías, por parte de los docentes, respecto al valor e impacto de la educación espiritual e integral en relación con las políticas educativas y cómo todos estos elementos inciden, finalmente, en sus prácticas pedagógicas para el desarrollo espiritual de los estudiantes. Por último, se discute en torno a los hallazgos y las posibilidades de ampliación de este estudio.

Palabras Clave: Teorías subjetivas; Educación integral; Educación espiritual; Política educacional.

\section{Abstract:}

Teachers of primary and secondary education that instruct different subjects were studied, by means of the ressources that the qualitative methodology offers, based on grounded theory elements. The results report the elaboration of theories by teachers, regarding the value and impact of the spiritual and integral education related to the educational policies and how all this elements have an impact on their pedagogical practices for the spiritual development of the students. Lastly, the findings and possibility of widening this study are discussed.

Keywords: Subjective theories; Integral education; Spiritual education; Educational policy. 


\section{Introducción}

Desde la Declaración Universal de los Derechos Humanos, en 1948, donde se declara que la educación apunta al "pleno desarrollo de la personalidad humana" (art. 26), la búsqueda y promoción de una educación integral ha estado presente en diversas instituciones internacionales que, agrupadas en el Foro Mundial sobre Educación, declaran, en su última versión celebrada el 2015 en Incheon: "Nos comprometemos con carácter de urgencia con una agenda de la educación única y renovada que sea integral, ambiciosa y exigente, sin dejar a nadie atrás" (Organización de las Naciones Unidas para la Educación, la Ciencia y la Cultura [UNESCO], 2016, art. 5).

Chile no ha quedado indiferente a las orientaciones internacionales. En la actualidad y principalmente por la reforma iniciada con la Ley General de Educación, la educación integral ha tomado gradualmente protagonismo en el marco normativo, declarando objetivo de la educación el "...desarrollo espiritual, ético, moral, afectivo, intelectual, artístico y físico..." (Ley № 20.370, 2009, art. 2) de las personas

El Proyecto Educativo Institucional (PEI) es otro elemento que tiene una relevancia central en el sistema escolar chileno, en la medida que en él se explicita cuáles son los sentidos y el sello que caracteriza a cada establecimiento y cuál es el aporte que realiza al desarrollo de su comunidad (Ministerio de Educación [MINEDUC], 2015). Según datos oficiales reportados en las fichas de los establecimientos educacionales chilenos, con financiamiento estatal o compartido (Villalobos y Salazar, 2014), la gran mayoría de proyectos educativos se centran en tres orientaciones o focos: a) el desarrollo integral de los estudiantes, b) la excelencia académica, y c) el desarrollo valórico.

Como se ve, en las políticas que orientan la educación chilena, se ha visibilizado una directriz con énfasis en la inclusión y la integralidad en la educación como elementos esenciales para el desarrollo del país en un contexto de globalización. La relevancia de este tema no es superficial. Necesitamos de una nueva actitud para el desarrollo humano que permita relacionarnos con el mundo y los seres que lo conforman de manera distinta.

En este contexto, problemas como la falta de alimentos, la inequidad social, el excesivo individualismo, la falta de empatía, el desconocimiento de la alteridad y la destrucción ambiental requieren que dejemos de pasar por alto la gran importancia que tiene el desarrollo espiritual como elemento transformador de nuestra manera de concebir el propio desarrollo y el de las sociedades (Sfeir-Younis, 2009; Benavent Vallés, 2014; Palacio Vargas, 2015).

En Chile, entre los años 2016 y 2018 se presentan los documentos que organizan y nutren las bases curriculares para $7 \mathrm{mo}$ a 2do medio (Ministerio de Educación [MINEDUC], 2015b) y 1ro a 6to (Ministerio de Educación [MINEDUC], 2018) respectivamente. Los documentos profundizan en la necesidad de trabajar de manera transversal la educación espiritual, declarando objetivos que dicen relación con reconocer y reflexionar sobre la finitud humana, y su dimensión trascendente y/o religiosa, agregando en el caso de los niveles mayores la pregunta por el sentido de la existencia humana. Por otro lado, 
actualmente los programas de religión católica se encuentran en proceso de reformulación y las informaciones preliminares apuntan a una distinción -aunque en relación- entre desarrollo religioso, valórico y espiritual (Conferencia Episcopal de Chile, 2020).

Las teorías subjetivas consisten en aquel saber que los sujetos organizan de manera argumentativa en paralelo y con características similares al saber científico-teórico, pero sin pretensión de universalidad (Brighenti Bortoluzzi y Catalán Ahumada, 2014). La preocupación por la educación para el desarrollo espiritual ha alcanzado una relevancia explícita en las políticas nacionales de los últimos 5 años, sin embargo, después de buscar investigación científica que trate la educación para el desarrollo espiritual en directa relación con los profesores de Chile, se constata que es muy escasa o incipiente. A partir de todo lo expuesto y dado el rol protagónico que juegan los docentes en el proceso educativo, es que se precisa el problema formulando la siguiente pregunta: ¿Cuáles son las teorías subjetivas sobre educación espiritual como parte de la educación integral que manifiestan profesores del sistema escolar?

La pertinencia de la investigación está dada por la actual necesidad de esclarecer si la noción de educación espiritual se encuentra presente en los docentes, y de ser así, qué tan alineada está con las corrientes académicas y políticas nacionales, además de su fundamento a partir de las teorías subjetivas. Al finalizar la investigación se busca proveer de una referencia con rigor científico que pudiese utilizarse para la formulación de planes de acción y/o programas de estudio sobre educación para el desarrollo espiritual, para detectar debilidades y/o necesidades respecto a la capacitación de equipos docentes en la materia o como antecedente para futuras investigaciones.

\section{Objetivos}

Considerando los antecedentes ya señalados, y de acuerdo con el problema planteado, esta investigación de carácter descriptiva-interpretativa considera los siguientes objetivos:

\subsection{Objetivo general}

Interpretar las teorías subjetivas sobre el concepto de educación espiritual que sostienen profesores de enseñanza básica y media, estableciendo semejanzas o diferencias con lo declarado por el ministerio de educación de Chile en las políticas educacionales vigentes.

\subsection{Objetivos específicos}

1. Describir la estructura manifiesta de las teorías subjetivas de los decentes de enseñanza básica y media de La Serena en relación con la educación espiritual.

2. Analizar los pensamientos de un grupo de profesores en torno a las prácticas docentes relacionadas con educación espiritual. 
3. Establecer semejanzas o diferencias entre las teorías subjetivas de profesores de enseñanza básica y Media de La Serena con lo declarado en las políticas educativas vigentes.

\section{Marco teórico}

\subsection{Educación integral}

Ya en 1973 la UNESCO, en el documento de Faure, et al. "Aprender a ser: la educación del futuro", se enfatiza en la necesidad de equilibrar los esfuerzos en educación para promover el desarrollo de las personas, tanto en el aspecto cognoscitivo como en otros que completan su complejidad. La idea principal era descentralizar el foco de los valores materiales, que apuntan más bien a lo conceptual-procedimental, para en su conjunto promover el cultivo de valores espirituales, refiriéndose a la posibilidad de una humanidad capaz de desenvolverse en el respeto de la pluralidad del mundo en el que vive.

La educación tal como ella funciona, la enseñanza tal como se imparte a los adolescentes, la formación que los jóvenes reciben, la información a la cual el hombre no puede sustraerse, todo contribuye, quiérase o no, a esta obra de disociación de los elementos de la personalidad. Para las necesidades de la instrucción se ha destacado arbitrariamente una dimensión del hombre, la dimensión intelectual bajo el aspecto cognoscitivo, y se han olvidado o descuidado las otras dimensiones, que se encuentran reducidas a su estado embrionario o se desarrollan de una manera anárquica. So pretexto de las necesidades de la investigación científica o de la especialización, se ha mutilado la formación completa y general de numerosos jóvenes. En el caso de ciertos trabajos, muy fragmentados o embrutecedores, la formación técnica sobreestima la importancia de la mejora de las aptitudes prácticas, en detrimento de otras cualidades humanas. (Faure, et al., 1973, p. 234-235)

En la década del 90, la idea sigue su desarrollo y frecuentemente podemos encontrarla en documentos de la UNESCO que buscan tanto orientar el quehacer educativo como motivar una nueva comprensión del mismo. Se advierte, en la educación, la posibilidad de contribuir a la disminución de la violencia y la inequidad en las relaciones sociales interpersonales e internacionales, insistiendo en otros aspectos de la educación que complementan el desarrollo de la persona. Delors, et al. (1996) en un informe a la UNESCO sobre los desafíos para la educación en el siglo XXI, donde se pregunta por la posibilidad de una educación que permita la solución pacífica de los problemas y el interés por las otras culturas y su espiritualidad, señalando que la educación debe apuntar a una concepción más amplia de sí misma, alejándose de lo meramente instrumental y considerando a la persona en toda su plenitud.

Según Álvarez Rodríguez (2001), sobre Educación Integral, en un enfoque axiológico, destacan los aportes de García Hoz (1991), Marín Ibañez (1993) y particularmente Gervilla Castillo $(1993,2000)$. Es importante mencionar que los 3 autores se refieren a la educación integral incorporando directa o indirectamente distintas dimensiones y valores del desarrollo personal como lo material, biológico, intelectual, social, político, ético, y espiritual. 
Por lo tanto, "La expresión educación integral, aunque puede interpretarse en sentidos muy variados, todos ellos incluyen el concepto de totalidad: la educación del hombre completo, de todas y cada una de sus facultades y dimensiones" (Gervilla Castillo, 2000, p. 41). Esta noción mantiene plena vigencia y, tal como lo indican Sánchez y Pérez (2017), actualmente representa uno de los más grandes desafíos en materia de educación:

La aspiración máxima del humanismo en la educación es la formación integral de la personalidad, del ser y su plena realización como ser humano, y el cultivo de la sensibilidad para desarrollar sus verdaderas potencialidades creadoras, lo que puede lograrse por medio del proceso de enseñanza aprendizaje, en el cual debe estar como un indicador. Además de lo anteriormente analizado, el proporcionar que el estudiante aprenda a pensar, sentir, actuar y desarrollarse como personas. (Sánchez Andrade y Pérez Padrón, 2017, p. 267)

\subsection{Educación espiritual}

Como se advierte en el punto anterior, la educación integral consiste en la complementariedad entre la búsqueda del desarrollo intelectual, material, ético, emocional, afectivo y espiritual. El cultivo de la dimensión espiritual del ser humano representa una gran oportunidad para un sentido armónico de la propia existencia, favoreciendo la convivencia entre seres humanos y la de estos con el medio ambiente. Sobre esta idea profundizan ampliamente, por ejemplo, los trabajos de Boff refiriéndose a la "espiritualidad del universo" (Boff, 1996) y Panikkar, especialmente su desarrollo del concepto de "Ecosofía" (Meza Rueda, 2010; Beltrán Marín, 2018).

En el área de la educación, el concepto no se aleja de su sentido clásico. Una primera intuición se advierte en algunos modelos educativos divergentes del siglo pasado y que focalizaron su atención en la emocionalidad y los valores que permiten abordar el proceso educativo otorgando a este un sentido profundo:

La educación espiritual de los niños es un tema que fue estudiado ya en la segunda mitad del siglo XX por pioneros en el ámbito pedagógico como Pestalozzi, María Montessori y, antes que ellos, por Rudolf Steiner. Parten de los modelos educativos que luego dieron pie a instituciones escolares fundadas en sus carismas e ideales educativos. Relacionan la espiritualidad infantil con la búsqueda de sentido y de significado, con la conexión con los otros, la naturaleza, el mundo entero y lo que trasciende toda la realidad. (Torralba Roselló, 2016, p. 101)

El interés por el desarrollo de la inteligencia espiritual (ÍES) tiene sus antecedentes en los trabajos de Howard Gardner en 1983 y David Goleman en 1995 que tratan las inteligencias múltiples y la inteligencia emocional (IE) respectivamente. El tema toma mayor impulso cuando en 1999 Gardner analiza la posibilidad de una ÍES, reconociéndola más bien como una inteligencia existencial indicando que esta corresponde a:

...la capacidad de situarse uno mismo en relación con las facetas más extremas del cosmos - lo infinito y lo infinitesimal-, y la capacidad afín de situarse uno mismo en relación con determinadas características existenciales de la condición humana, como el significado de la vida y de la muerte, el destino final del mundo físico y del 
mundo psicológico, y ciertas experiencias como sentir un profundo amor o quedarse absorto ante una obra de arte. (Gardner, 1999, p. 48)

El concepto de IE cobra fuerza en los inicios del siglo XXI con los aportes de Zohar y Marshall y se podría definir como la capacidad de encontrar sentido a la existencia, de manera situada y en relación con un todo ordenado, impulsándonos a buscar la plenitud y desarrollar la profundidad y sentido de nuestro ser (Rodríguez, 2013; Torralba Roselló, 2010). Aunque Zohar y Marchall (2001) relacionan la IE con diversos temas, uno de los más interesantes es el estudio desde la neurociencia, afirmando una relación directa entre el cultivo de la espiritualidad y la reacción bioquímica del sistema nervioso que se corresponde con nuestra capacidad de otorgar sentido en cuanto razón de ser.

Nos parece necesario aclarar que la ÍES, si bien tiene relación con la religión, no depende de una fe particular para su desarrollo, por lo tanto, la educación para el cultivo de la ÍES de ninguna manera debe asumirse como una cuestión puramente confesional. Como veremos, el llamado a hacerse cargo de esta dimensión está dirigido a todas las escuelas y es tan relevante como el que los profesores comprendan y lleven a la práctica acciones para una educación que aporte al desarrollo espiritual de su comunidad educativa. Al respecto, Rodríguez (2013), destaca la necesidad de educar en este sentido tanto en las escuelas como a los docentes en formación, asumiendo la responsabilidad indirecta de la formación de los jóvenes y niños en las escuelas, y agrega que “... la IE no está casada con alguna religión; es decir, existen personas religiosas que no tienen por qué manifestar alguna IE, mientras existen otras personas que no siendo religiosas manifiestan un alto grado de IE" (Rodríguez, 2013, p. 19).

Como hemos revisado y como señala Torralba Roselló (2010) al profundizar en este aspecto, el estudio sobre el tema se ha incrementado al punto que, en la actualidad, diversos autores están alineados con la idea de la ÍES como un elemento más de las inteligencias múltiples, agregando este que la IE "faculta para tener aspiraciones profundas e íntimas, para anhelar una visión de la vida y de la realidad que integre, conecte, trascienda y de sentido a la existencia" (p. 52).

Como hemos visto, el abordaje del tema a nivel internacional es bastante reciente y en Chile, particularmente, la preocupación por el desarrollo de la dimensión espiritual en la educación formal lo es aún más y, si bien antes de la Ley General de Educación existían algunas menciones, orientaciones más específicas son materia de la última década.

\subsection{Política educativa y educación para el desarrollo espiritual}

En el 2009, a la conocida cita del Art. 2 que define y declara el propósito de la educación en Chile, persiguiendo el "... desarrollo espiritual, ético, moral, afectivo, intelectual, artístico y físico..." (Ley № 20.370, 2009, art. 2) de las personas, se suma lo declarado explícitamente en la misma en su Art. 10 "Los alumnos y alumnas tienen derecho a recibir una educación que les ofrezca oportunidades para su formación y desarrollo integral..." (Ley № 20.370, 2009, art. 10, a) y artículos 18, 19 y 28 que se refieren a las etapas de educación parvularia y básica. Claramente se evidenciaba una dirección hacia la integralidad en educación, sin embargo, la ley no declara explícitamente aquello que entenderemos por 
educación integral, remitiéndonos de manera casi intuitiva a lo ya citado del Art. 2. Sin embargo, y aunque ya en el año 2009 la necesidad de una educación integral en todos los niveles se leía implícitamente en todo momento en la ley, queda más claro con la Ley de Inclusión Escolar que regula la admisión de los y las Estudiantes, elimina el financiamiento compartido y prohíbe el lucro en establecimientos educacionales que reciben aportes del Estado (Ley $\left.\mathrm{N}^{\circ} 20.845,2015\right)$, específicamente con la incorporación del principio de Educación Integral al Art. 3 de la Ley № 20.370 (2009), que establece los principios en los que se inspira el sistema educativo escolar chileno en su totalidad. Este nuevo principio declara:

El sistema educativo buscará desarrollar puntos de vista alternativos en la evolución de la realidad y de las formas múltiples del conocer, considerando, además, los aspectos físico, social, moral, estético, creativo y espiritual, con atención especial a la integración de todas las ciencias, artes y disciplinas del saber. (Ley № 20.845, 2015, art. 1, g)

Desde entonces, en las políticas que orientan la educación chilena, se ha visibilizado una directriz con énfasis en la inclusión y la integralidad en la educación como elementos esenciales para el desarrollo del país en un contexto de globalización, resaltando la necesidad de un cambio desde el paradigma en el que los estudiantes eran el recipiente de los conocimientos, hacia la formación de personas integrales, en un proceso de socialización que promueva el sentido de ciudadanía, el espíritu crítico y el compromiso con la propia persona y el entorno (Ministerio de Educación [MINEDUC], 2017). Por lo tanto, la educación chilena se alinea con una educación integral para todos, en búsqueda del desarrollo pleno de las distintas dimensiones que en su conjunto conforman lo humano, coincidiendo además con lo declarado por los autores citados.

En Chile, en el 2013 aparecen las bases curriculares para la asignatura de orientación de 1ro a 6to básico, mencionando sólo una vez la palabra espiritualidad cuando en su introducción cita el Art. 2 de la Ley № 20.370 (2009); y la palabra religión, sin mucho protagonismo, sólo cuando se habla de evitar discriminación (Ministerio de Educación [MINEDUC], 2013). En el año 2016 y 2018 se presentan los documentos que organizan y nutren las bases curriculares para $7 \mathrm{mo}$ a 2 do medio (MINEDUC, 2015b) y 1 ro a 6to (MINEDUC, 2018) respectivamente. La palabra espiritualidad aparece nuevamente en medio de citas a la Ley General de Educación, pero esta vez se menciona entre los principios valóricos sobre los cuales se construyen las bases de "...las tradiciones espirituales del país" (MINEDUC, 2015b, p. 16; MINEDUC, 2018, p. 20) y la búsqueda de la "... mayor realización espiritual y material posible" (MINEDUC, 2015b, p. 18; MINEDUC, 2018, p. 20). En el documento de enseñanza básica se declaran 32 objetivos de aprendizaje transversales distribuidos en 7 dimensiones, mientras que en el de $7 \mathrm{mo}$ a 2 do medio 38 objetivos en 9 dimensiones. En ambos, la dimensión afectiva declara "...la importancia que tienen las dimensiones afectiva, espiritual, ética y social para un sano desarrollo sexual. Apreciar la importancia social, afectiva y espiritual de la familia para el desarrollo integral..." (MINEDUC, 2015b, p. 26; MINEDUC, 2018, p. 29). Además, en ambos documentos la espiritualidad es en sí una de las dimensiones y busca promover "...la reflexión sobre la existencia humana, su sentido, finitud y trascendencia, de manera que los estudiantes comiencen a buscar respuestas a 
las grandes preguntas que acompañan al ser humano" (MINEDUC, 2015b, p. 27; MINEDUC, 2018 , p. 30). Los objetivos que se declaran para la dimensión espiritual dicen relación con reconocer y reflexionar sobre la finitud humana, y su dimensión trascendente y/o religiosa, agregando en el caso de los niveles mayores la pregunta por el sentido de la existencia humana.

Por lo tanto, una educación que busque el pleno desarrollo de las personas “...para convivir y participar en forma responsable, tolerante, solidaria, democrática y activa en la comunidad, y para trabajar y contribuir al desarrollo del país" (Ley № 20.370, 2009, art. 2), debe hacerse cargo de la dimensión espiritual para favorecer un abordaje responsable y comprometido que nos oriente hacia soluciones cada vez más urgentes respecto a las necesidades de la sociedad actual.

\subsection{Teorías subjetivas}

El concepto de Teorías Subjetivas (TS) se remonta a los aportes de Groeben y Scheele (1977) quienes refieren a la capacidad del ser humano de conocer e interpretar en base a una estructura argumentativa implícita que cumple funciones análogas a las teorías científicas. Esta primera definición es complementada por Flick (1991), para quien tratan principalmente de las explicaciones fundadas en la experiencia particular de los sujetos que finalmente constituyen un tipo de conocimiento y modelos explicativos con incidencia en su comportamiento respecto a algo determinado.

Para Catalán Ahumada (2010), las TS hacen referencia a las explicaciones que los sujetos elaboran sobre los objetos o sobre sí, sin necesidad de demostraciones rigurosas como las teorías científicas aunque con el mismo efecto ordenador de la realidad y antecedente para las relaciones sociales y el comportamiento del sujeto. Alejadas de un enfoque positivista, las TS se enmarcan en un paradigma interpretativo que considera epistemológicamente al sujeto investigado como agente de interpretación y no como objeto de interpretación (Catalán Ahumada, 2016).

Además, las construcciones explicativas que sostienen los sujetos se caracterizan por una argumentación que básicamente se manifiesta en la estructura antecedenteconsecuencia, expresada lingüísticamente en formulaciones tipo si-entonces y que teóricamente expresan causa-efecto, pudiéndose clasificar según su organización y poder explicativo en los niveles preteórico, teórico restringido y teórico (Catalán Ahumada, 2010).

\section{Metodología}

El tipo de diseño de la investigación, que según Canales Cerón (2006) corresponde al plan que integra de manera coherente la formulación de objetivos, la técnica de recolección de datos y el modelo de análisis, es de tipo interpretativo y por tanto sigue una metodología cualitativa. Es decir, se trata de "un proceso de indagación para la comprensión de problemas sociales u humanos, basado en la construcción de cuadros/descripciones (pictures) formados en base a palabras, dando cuenta detalladamente de la perspectiva de los informantes, y conducido en un escenario natural" (Creswell, 1994). Nos referimos a una búsqueda 
interpretativa bajo estándares subjetivos, accediendo al objeto desde el sujeto. Para este caso, el diseño está basado en elementos de la teoría fundamentada definida en 1967 como una "aproximación inductiva en la cual la inmersión en los datos sirve de punto de partida del desarrollo de una teoría sobre un fenómeno" (Guillemette, citado en Páramo Morales, 2015, vii), se trata de "... una metodología para descubrir teorías que dormitan en los datos" (Strauss citado en Cuesta Benjumea, 2006, p. 136).

La investigación es de tipo descriptiva, persigue la recolección de datos sobre el fenómeno de manera no probabilística ya que se seleccionó a los miembros, que componen la muestra, a partir del juicio de los investigadores (Canales Cerón, 2006). El tipo de muestreo es no probabilístico y apunta a la variación máxima, documentando diferencias o patrones comunes importantes (Miles y Huberman, 1994).

Los criterios intencionados de selección de la muestra son el ejercer como profesor en instituciones de enseñanza básica o media de la región de Coquimbo y el contar con al menos dos años de experiencia en su ejercicio. La naturaleza del criterio se debe a la necesidad de contar con sujetos habilitados para desarrollar unidades de análisis relacionadas con políticas educativas y experiencias de aula que recién egresados podían no haber desarrollado o estar recién desarrollando.

La muestra está compuesta por sujetos con las siguientes características:

\begin{tabular}{ccc} 
Asignatura & Años de experiencia & Comuna en la que ejerce \\
Arte y Tecnología & 20 & Coquimbo \\
Matemática & 24 & La Serena \\
Química & 5 & La Serena \\
Lenguaje y Comunicación & 7 & La Serena \\
Historia & 15 & Río Hurtado \\
Historia & 3 & La Serena \\
Inglés & 5 & La Serena \\
Educación Física y Salud & 27 & La Serena \\
\hline
\end{tabular}

El estudio obedeció a la secuencia grabación, codificación, categorización y, finalmente, representación. En la etapa de grabación se establece un convenio de confidencialidad, motivando una participación auténtica de los entrevistados. Siguiendo los criterios de análisis propuestos por la teoría fundamentada, la investigación completó las fases de codificación abierta, identificando y separando los datos en diversas unidades semánticas -códigos- que representan un fenómeno general, y codificación axial, proceso en el que se establecen tipos de relaciones a partir de conectores lógicos entre códigos que conforman categorías específicas (Spiggle, citado en Cuñat Giménez, 2007).

La información se recogió a través de una entrevista en profundidad, gracias a sus rasgos de abertura y flexibilidad permite un vínculo especial con el entrevistado, el cual 
permite acceder a aspecto profundos a través del despliegue verbal con el que da forma a sus ideas sobre la realidad (Canales Cerón, 2006), recogiendo los datos para una investigación fenomenológica y así examinar detalladamente las experiencias que describen los sujetos (Creswell, 1994). El análisis de los datos recogidos con el instrumento se realizó con el Software Atlasti.

Respecto a los criterios de rigor científico se abordaron, durante la investigación, en el análisis de los relatos, su codificación y desarrollo de resultados, en un trabajo recíproco entre los investigadores, resguardándose la inclinación hacia las tendencias particulares de alguno de ellos, cumpliendo así con el criterio de triangulación (Taylor y Bogdan, 1984) de investigadores. En la etapa de codificación abierta, la información que proveyeron los entrevistados permitió cumplir con el criterio de saturación teórica, produciéndose un agotamiento de nuevas unidades semánticas. Esto indica que ya no es necesario aumentar el número de entrevistas, pues en la investigación cualitativa la repetición no provee de más información (Canales Cerón, M., 2006). Por último, se cumple con la auditabilidad a través del registro completo de los pasos y decisiones tomadas durante la investigación (Salgado Lévano, 2007), pudiendo otro investigador recurrir a grabaciones, registros textuales de ellas y registro de códigos.

\section{Resultados}

Al finalizar la etapa de codificación abierta se obtuvo como resultado un corpus con 8 documentos primarios que a su vez generaron un listado de 73 códigos. Al notar la frecuente aparición de los códigos ya creados se logra la saturación, por lo que de ampliar el corpus no se habría producido mayor generación de información relevante. A partir del análisis de los códigos, las categorías construidas en la etapa de codificación axial fueron: Contexto, Políticas Educativas, Educación Integral, Educación para el Desarrollo Espiritual y Prácticas Pedagógicas.

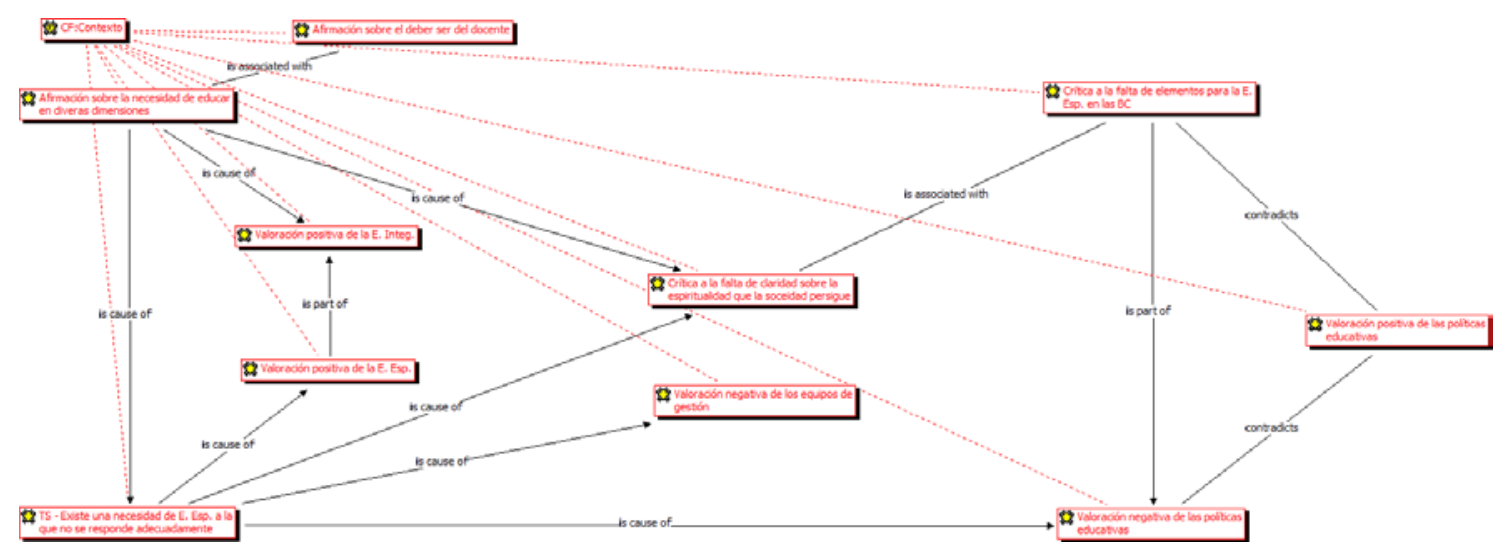

Grafo 1: Contexto

El grafo 1 nos muestra los elementos fundamentales a partir de los cuales los sujetos manifiestan sus ideas en las entrevistas, permitiendo una mayor comprensión del fenómeno estudiado. Se muestra una predominancia de relaciones transitivas en las que se establecen 
causalidades entre los elementos de contexto. La necesidad de educar en diversas dimensiones expresada por los sujetos se muestra en relación simétrica con el deber ser al que estos se sienten llamados.

Sujeto 1: Hablamos mucho de formación integral, de educar para formar ciudadanos de bien, pero no los vamos a poder formar si solo priorizamos el lado científico o matemático. El conocimiento debe ir de la mano con lo valórico, sino ¿Qué vamos a tener? ¿Ciudadanos como los de ahora? ¿Que solo piensan en ellos y no en los demás?

De esta asociación surgen teorías subjetivas referentes a la necesidad de Educación Espiritual a la que la sociedad no responde. Los sujetos significan esta necesidad argumentando en un nivel teórico restringido y si bien evidencian un conocimiento más bien intuitivo del concepto de educación espiritual, lo que queda de manifiesto en su crítica a la falta de elementos para ésta en la Bases Curriculares o en otros aspectos de la política educativa, se visualiza su hipótesis respecto a la falta de compromiso de nuestra sociedad con la educación espiritual.

Sujeto 3: Pucha, es que si yo lo veo así ... como yo soy creyente, yo soy cristiana, yo siento que la educación espiritual aquí en Chile no hay. Porque yo hablo con las personas y no tienen idea, así como en su espiritualidad, no saben qué creen, no saben en qué no creen, si creo en las energías, "no yo creo en Dios...", "no yo creo en la Virgen..." no sé qué. Entonces claro, existiría una necesidad por parte de que, no sé si la escuela ah... brinde eso, pero que de alguna manera se tome este tema, porque yo siento que no se está abordando.

Destaca, además, una valoración positiva de la educación integral y de la educación espiritual como parte de ésta, derivando en una crítica a la falta de claridad sobre la espiritualidad que la sociedad persigue, principalmente porque las políticas educativas no se hacen cargo de ello.

Sujeto 7: Sí, sí, la parte espiritual es una pieza más del componente del ser humano. Digamos que al ser humano lo dividimos en varias partes, esa es una más.

Sujeto 2: quizás, a lo mejor ahí habría que dejar bien en claro el valor espiritual que quiere la sociedad trabajar.

Aun así, existe una relación asimétrica entre la valoración negativa de las políticas educativas y la valoración positiva a las mismas. Los sujetos perciben buenas iniciativas en las políticas educativas sin acabar por estar conformes o sentirse representados por ellas.

Sujeto 4: Creo que los programas de primero y segundo medio, que son los nuevos, si, tienen mucho de educación integral porque no se espera que los niños aprendan solamente contenidos.

Sujeto 3: Yo siento que el currículum es demasiado Academicista. 


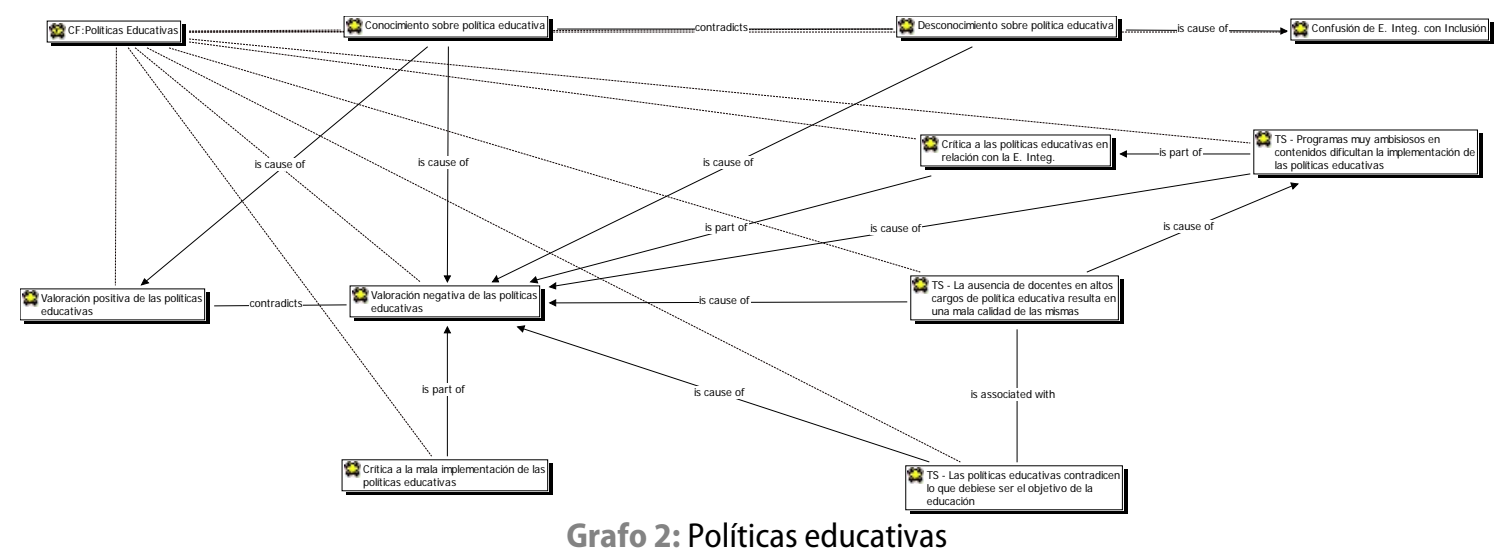

El grafo 2 muestra la valoración que expresan los sujetos sobre el rol de las políticas educativas en relación con la educación integral. Junto con la relación asimétrica entre la valoración positiva y la valoración negativa de las políticas educativas, se observa como esto se origina en la contradicción de los elementos conocimiento y desconocimiento de las políticas educativas.

Sujeto 3: Ahora, dónde podemos encontrar, así como esa información, son lo que rige las bases y el marco curricular que tiene el MINEDUC, junto con las propuestas que ellos suben continuamente de mejora hasta estos mismos temas.

Sujeto 5: Una educación integral, según mi visión, es que tiene que aceptar, aceptar a todos los chicos.

Como se observa en el grafo, el foco está dirigido hacia la valoración negativa de las políticas educativas, a través de relaciones de tipo transitivas. Apuntando a este foco, destaca la elaboración de teorías subjetivas, nuevamente en un nivel teórico restringido. Los sujetos perciben la ausencia de docentes en altos cargos de dirección pública concernientes con políticas educativas como un aspecto causal de la mala calidad de estas, cuestión asociada a una visión de las políticas educativas como contradictorias entre aquello a lo que estas apuntan y lo que debiesen tener por objeto.

Sujeto 6: Eh... Uh, difícil. Difícil rescatar algo con una ministra que no es profesora, me parece que es complejo porque al fin y al cabo lo que pasa con eso es que al ella nunca haber hecho clases y al no haberse posicionado nunca con un libro de clases o un cierre de semestre, es muy difícil que nos entienda a los profesores que sí estamos en el día a día con eso. La verdad no sé si habría alguna política pública que yo podría rescatar.

Sujeto 4: No tengo tanta claridad a esa pregunta, pero sí, tengo claridad, porque lo he vivido en este cambio a Piñera, de Bachelet a Piñera, de que obedece a cuestiones políticas y ahí, la idea de educación cambia, cambia por que los libros que vienen del ministerio son distintos, enseñan cosas distintas, las propuestas curriculares son distintas, entonces yo creo que en realidad nosotros hablamos de educación, pero más como para cumplir, no veo que, que que en realidad haya mucha importancia como sociedad de la educación, y el fin último, yo creo que es prepararlos para que sean buenos trabajadores, no solamente a nivel como ministerial, sino que yo creo que los directores de muchos colegios también tienen esa idea, porque siempre, por ejemplo los niños que les va mal, todavía hay directores y profesores que les dicen: Ya, pero tú tienes que ser ordenado, 
responsable, porque ya no tienen expectativas en que lleguen a la universidad, sino que por último que sea un buen trabajador, responsable, que llegue a su trabajo todos los días.

Finalmente, otro elemento central en el grafo es la crítica a las políticas educativas en cuanto a la educación integral, esto en relación con la percepción de los sujetos sobre los programas curriculares. Para los sujetos, la alta exigencia de aprendizajes específicos de las asignaturas sería más bien un obstáculo para poder trabajar la integralidad que se pretende a partir de lo declarado en las políticas educativas.

Sujeto 3: yo siento que el... o sea, según lo que yo veo en realidad del análisis que yo he hecho, ya llevo casi cinco años ya haciendo clases, el tema de ciencias es muy extenso. La parte académica es demasiado extensa, entonces yo no puedo tomarme el tiempo de que los niños tengan un aprecio, por así decirlo, tan grande por el contenido o por el tema porque no le puedo mostrar todas las aristas. La parte valórica, de por qué ese científico hizo esto en este contexto, qué significa por ejemplo que un científico haya trabajado durante la época de la guerra fría, que eso igual es súper interesante que ellos lo sepan, por eso ellos estaban ahí no se po', tan máquina ahí trabajando.

¿Entonces asuntos que son más bien de sentido, del por qué...?

Claro. Quedan un poquito más relegados y es como que se intenta mezclar un poco con la parte académica pero no llega a darse la profundidad que a mí me gustaría.

¿Entonces está más centrado en el cómo se hacen las cosas más que en el por qué y el para qué?

Claro.

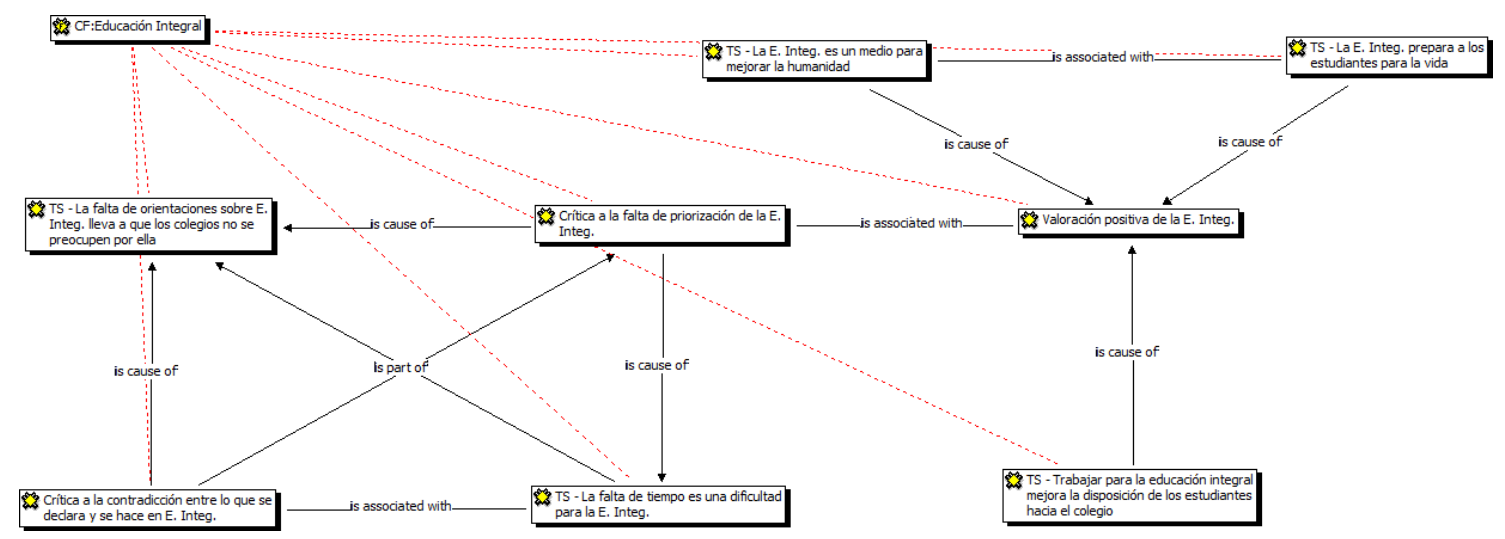

Grafo 3: Educación integral

El grafo 3 nos muestra principalmente teorías subjetivas de los sujetos y cómo estas influyen en su valoración sobre la educación integral. Destacan las relaciones de tipo transitiva, aunque también se observan elementos en relación simétrica, como la concepción que los sujetos tienen de la educación integral como un medio para mejorar la humanidad en asociación con que la educación integral prepara a los estudiantes para la vida.

Sujeto 1: para mí es prioritaria porque el objetivo último de la escuela debería ser formar personas que puedan vivir en una sociedad, y en lo posible a contribuir para que dicha sociedad sea cada vez mejor, entonces, la única manera de mejorar esta 
sociedad es formar a las personas en algo más que un contenido, que, en último caso, a lo mejor se van a utilizar para rendir una prueba, como la PSU o el SIMCE, por ejemplo.

Sujeto 3: Claro. Es que lo ideal es educar para la vida, porque en el fondo el trabajo, cuando uno llega te capacitan y en el fondo te van... tú vas a poder trabajar ahí. Pero en el tema es como te desempeñas las habilidades que tú tienes para trabajar con otras personas, el ser colaborativo, no ser tan competitivo, esas cosas que son actualmente, que no se están fomentando y que eso apuntan las nuevas políticas.

La valoración positiva de los sujetos hacia la educación integral constantemente va de la mano con una crítica a la poca relevancia que le damos al tema como sociedad y a la contradicción que se da al contar con grandes declaraciones en lo formal, pero sin ocuparnos de llevarlas a la práctica.

Sujeto 8: Para ser optimista... A ver, cuando ellos hablan de... que es lo que yo creo en realidad como un individuo integral, yo creo que hablan de una persona que va a desarrollarse en todas sus áreas: físicamente, emocionalmente y espiritualmente como un individuo de bien, pero yo siento que el tema de la competitividad, las mediciones, las estandarizaciones no nos llevan a eso."

Sujeto 1: Bueno, ya es obligatoria, aunque en algunos casos, cuando está declarada en el proyecto educativo... ahora que se cumpla, es otra cosa.

¿Entonces no siempre es así?

Bueno, por lo menos en los lugares en los que he trabajado, a veces se trataba de hacer y se desarrollaban acciones para ello, pero en otros no pasaban de ser declaraciones que quedaban en el papel.

En esa línea, los sujetos elaboran teorías subjetivas acerca de cómo la falta de orientaciones o de preocupación por parte de medios externos por recoger evidencias sobre educación integral lleva a que los colegios se despreocupen por el tema. Esto sumado a la excesiva preocupación por los objetivos de las pruebas estandarizadas, focalizadas en aprendizajes específicos de las asignaturas, que resulta en una falta de tiempo para trabajar por la integralidad.

Sujeto 1: ¿Tú crees que las bases curriculares, que se relacionan un poco con las políticas educacionales, crees que les dan énfasis, además de nombrarlos, crees que le dan la importancia que se merecen los objetivos transversales, pensando en que tienen que ver también con lo integral?

No, no, yo creo que no, porque al final, por ejemplo, el SIMCE no mide nada transversal.

¿y aparte de estar declarados, que te impulsa, o que te obliga a aplicar estos objetivos, de alguna manera? ¿Hay alguna forma en que el colegio, o el ministerio, o las bases te señalen como: mira, usted tiene que hacer esto para que esto funcione?

No, lo dejan ahí, al antojo, y por eso que en general los colegios ni siquiera se preocupan de eso.

Sujeto 3: Lamentablemente no se puede hacer así porque en honor al tiempo igual las actitudes toman más tiempo en formarse que un contenido, entonces... y si mi 
currículum ya es amplio y tengo que poner el foco ahí, ya se hace un poquito más difícil y complicado.

Por último, se observa cómo, para los sujetos, la educación integral podría modificar la actitud de los estudiantes hacia el colegio en relación con la valoración positiva de los docentes hacia ésta. En este punto, si bien la teoría no cuenta con una alta frecuencia en la etapa de codificación abierta, el sujeto la sostiene como un elemento relevante en cuanto al impacto que podría generar la educación integral en el sistema educativo.

Sujeto 7: Yo sé que hay personas que son más...como se dice, enchapados a la antigua, que es como "al colegio se va a estudiar"... "del colegio a la casa y de la casa al colegio", que a veces, quizás, como que no les llama la atención, o no ven que en la educación se pueden tomar esos, esos valores, el aprender, el integrarse, también se pueden adaptar en la educación. Lo ideal sería eso, sería genial porque así los niños...le cambia su visión también del colegio que no solamente es llegar, abrir el cuaderno, el libro, poner atención, escribir, decir presente y hasta luego.

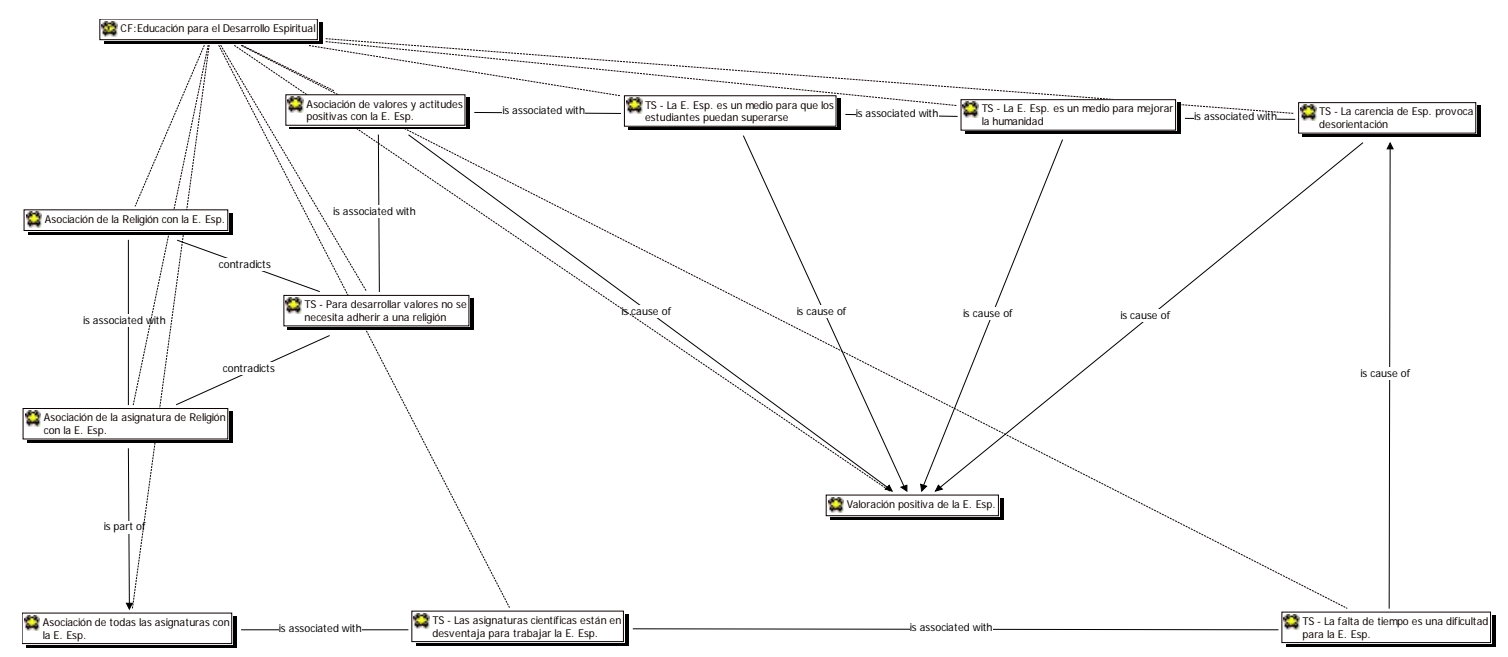

Grafo 4: Educación para el desarrollo espiritual

El grafo 4 muestra teorías subjetivas recogidas a partir de lo que los sujetos expresan y cómo estas influyen en su noción y valoración sobre la educación espiritual. Un elemento de significación es la asociación de valores y actitudes positivas con la educación espiritual y cómo esto se presenta en relación simétrica con la idea de que para desarrollar valores no se necesita adherir a una religión.

Sujeto 3: Para usted ¿Qué significa educar para el desarrollo espiritual?

Oh qué difícil. Ya. Educar para el desarrollo espiritual... bueno para mí la parte espiritual tiene que ver con el buscar yo el cómo me relaciono yo con otros aspectos más valóricos eh... más que académicos digamos.

Sujeto 2: Eh... ¿educar para el desarrollo espiritual? ...es para mí, como educar para la vida, porque si yo soy capaz de enseñarle valores, como te decía en un principio, no valores católicos, porque los valores son transversales, ¿ya?, una persona que sea agnóstica, que no crea en dios... ¿ya?, y que crea que hay algo superior que si existe, pero no se llama dios, va a tener unos valores pero importantísimos, y que puede quizás, a lo mejor, ayudar a un joven a su crecimiento ¿te fijas? 
Un segundo aspecto que muestra el grafo es la relación asimétrica que se da entre lo prescindible que resulta a los sujetos el adherir a una religión para desarrollar valores y la asociación que los mismos hacen de la educación espiritual con la religión bien como tema general o como asignatura.

Sujeto 7: en el caso en el colegio donde yo voy, que es un colegio evangélico, se le da mucho realce a eso, porque por ser evangélicos, se lee la biblia, se le da mucho, mucho al tema, en el caso del colegio que estoy yo, que es un colegio evangélico.

Sujeto 2: Hay un área que debería darle más énfasis, y que es área de religión, o todo lo relacionado con la pastoral del colegio.

Pese a al protagonismo que los sujetos otorgan a la asignatura de religión, estos no le atribuyen exclusividad en cuanto a la posibilidad de educar o desarrollar la espiritualidad de los estudiantes, visualizando la posibilidad de hacerlo en todas las asignaturas. Sin embargo, expresan una jerarquía acerca de cuáles estarían en mayor ventaja, siendo siempre estas las de la llamada área humanista.

Sujeto 8: Bueno, debería relacionarse con todas, yo creo que, obviamente, hay unas más relacionadas que otras.

Sujeto 6: ¿Te refieres principalmente al área humanista?

Claro, sí, sí. Principalmente al área humanista.

¿Y por qué será que el área humanista tiene mayor facilidad para eso?

Porque eso es lo que ofrece: Ia reflexión. El simple hecho de que nuestras pruebas sean de desarrollo apunta a eso, a la reflexión, no a la exactitud del pensamiento crítico, sino a la reflexión de acuerdo a un pensamiento histórico y un pensamiento en comunidad, siento yo.

Finalmente, sobresalen las teorías subjetivas que sostienen los sujetos, y de las cuales procede una valoración positiva de la educación espiritual, tanto por su importancia para el bienestar de la sociedad como por su impacto en la vida personal de los estudiantes, observándose una relación transitiva entre la falta de tiempo como una dificultad para trabajar el desarrollo espiritual y la carencia de ésta como elemento que resulta en la desorientación de los estudiantes.

Sujeto 1: ¿En qué fundamenta los aspectos que usted apunta a fortalecer en el desarrollo espiritual de sus estudiantes?

Básicamente, en formar mejores personas, en pensar que la única manera de que nuestro país se desarrolle como una sociedad mejor es ampliando lo que entrego en mi asignatura con algo, algún trabajo, algún tema que hagan que nuestros niños no solo trabajen construyendo algo, sino que ese algo tenga un sentido que vaya más allá de la sala o la nota."

Sujeto 5: ¿Qué experiencia de aula ha sido significativa para usted en relación con el aporte para la educación espiritual de sus estudiantes?

Bueno, después de 15 años yo creo que son hartas cosas. Pero, así como un ejemplo... Como un ejemplo... como un ejemplo, no sé, tal vez como términos generales nomas de pongamos, tal vez, la superación de mis estudiantes, el hecho de haber comenzado en un colegio en los cuales teníamos nosotros un 20 un 30\% 
de alumnos en educación superior, pasar a un $80 .$. un $80 \%$ de alumnos en educación superior y yo me siento responsable de eso y yo siento que... no lo siento conocimiento, sino le enseñé valores de superación, de esfuerzo, de sacrificio y eso así como un hecho específico, pienso no... tal vez unas clases que han ocurrido pero lo más significativo ha sido eso. Sentir que todo lo que conversé con ellos durante años al final se cumplió y eso creo que apunta la parte espiritual pensándolo bien.

Sujeto 3: Yo creo que, no sé, para mí la parte espiritual es súper importante, porque siento que de ahí se define como funcionamos nosotros, entonces, la parte espiritual que yo siento que a los chicos le falta, yo siento que a esta generación, en general le falta, provoca que haya muchas cosas que ellos no entiendan, y no procesen bien, por así decirlo, no se trata de una creencia de otra, o de una religión de otra, sino que se trata de... de que tener...yo siento que tener ordenada la casa, por así decirlo, tener ordenada esta parte espiritual, ello les ayuda a definir muchos aspectos de su vida, y yo siento que aparte de que a los niños yo los escucho, y es como que no saben para dónde va la micro, parte de eso, empieza ahí, que ellos no tiene claridad respecto a, a como son, a como es su, su ser espiritual.

Sujeto 7: la educación espiritual, incluirla dentro de, e incentivar a los profesores de que la practiquen con los niños. Yo sé que igual el profesor está atareado y lleno de trabajos y cosas que hacer, y que le digan... así como que, pucha otra cosa más que tenemos que enseñarles a los niños.

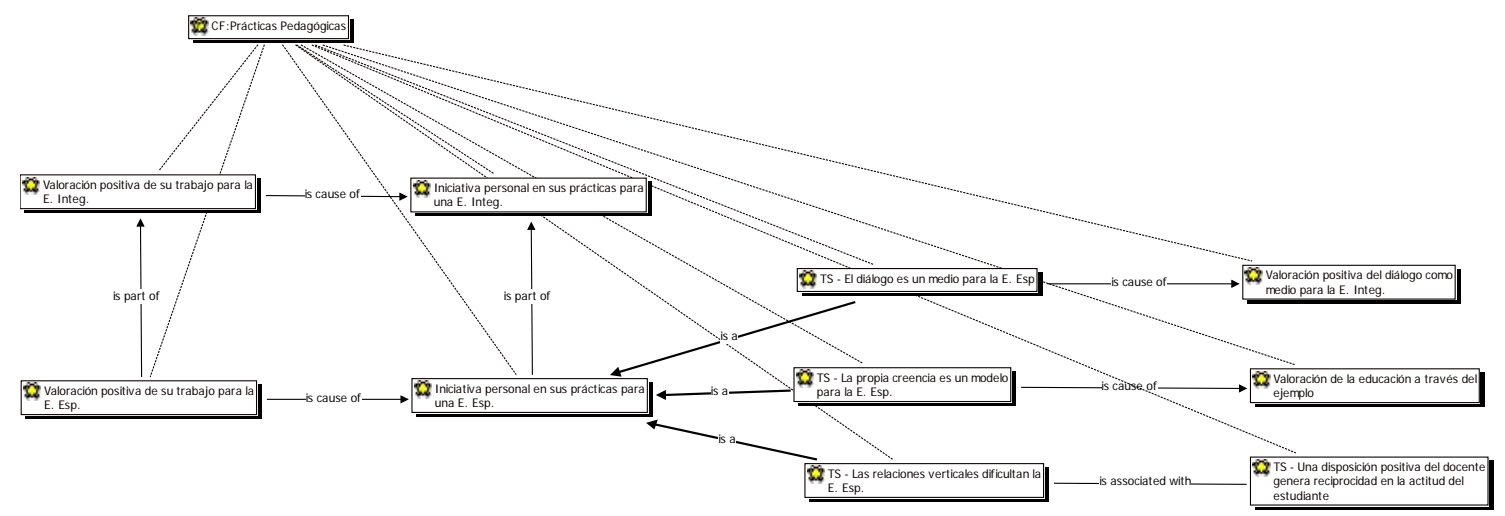

Grafo 5: Prácticas pedagógicas

El grafo 5 nos muestra las relaciones entre los elementos que refieren al trabajo concreto de los sujetos y las teorías que estos elaboran sobre ello. Se observa una alta valoración de su propio trabajo tanto por la educación integral como por la educación espiritual como parte de la primera, estas en relación transitiva con las propias iniciativas como fundamento para sus prácticas.

Sujeto 2: Sí, es más que nada eso, en cierto modo uno ve que está declarado en los planes y programas y de qué manera quizás podría uno actuar para hacer eso (educar para el desarrollo integral), pero más que nada sale de forma espontánea, muchas veces en forma espontánea, personal, conversarle a los chiquillos desde mi experiencia de estudiante, de mi vida, de las dificultades que tuve yo como estudiante en la educación media, en la educación universitaria.

Sujeto 6: No, yo (las directrices para trabajar el desarrollo espiritual de los estudiantes) lo saco desde mis iniciativas personales. Gran parte de lo que hago 
dentro de la sala de clases tiene que ver con un ámbito personal, porque es la manera como yo lo puedo abordar hacia... hacia los estudiantes. Desde la experiencia, desde el conocer, desde el viajar, un montón de aspectos que... que sirven para decirle a los chicos como "eso no es asi", "yo estuve allá" o "eso es así, porque lo puede apreciar de cerca".

Se observa, además, una relación simétrica entre la percepción de los sujetos respecto a la disposición positiva del docente hacia los estudiantes como un factor que propicia un clima de buenas relaciones junto a la idea de horizontalidad en las mismas como un facilitador para trabajar el desarrollo espiritual de los estudiantes.

Sujeto 2: Ayuda mucho, yo creo, porque a lo mejor predispone al alumno para que ya después de hablar de un tema que a lo mejor a él le gustó, el alumno mismo piense "bueno, ya que el profe estuvo atento a lo que, a lo que yo quería, voy a estar atento a lo que él quiere" ¿te fijas? Entonces, a lo mejor esta situación de compensación que pueda darse de parte del alumno, es decir, si el alumno y la alumna, y la niña y el niño ve que tú le escuchaste, de que tú le prestaste atención, de que tú lo apoyaste, que tú le diste, a lo mejor, una palabra de aliento, y sobre todo del que tú lo escuchaste, ¿ya?, puede que por compensación, el niño diga "bueno, ya que el profe me prestó atención, yo voy a estar dispuesto a prestarle atención.

Sujeto 6: Sí, la valoran mucho porque se disminuye esta brecha jerárquica entre el profesor, que es la autoridad, etc., que ellos lo saben, pero también entienden que detrás hay una persona que también estudió, que también tuvo errores, que los sigue teniendo, eh... que tiene miedo, etc. y ahí empiezan a comprender también al profesor, pero también al ok, Sergio Varela ex estudiante, ex universitario, incluso en relaciones interpersonales, relaciones amorosas, etc.

Finalmente, se observa que varios elementos apuntan hacia la valoración de las propias iniciativas en su trabajo para la educación espiritual, fundadas en una apreciación positiva de los sujetos tanto del diálogo como de sus propias creencias como medio para sus prácticas pedagógicas dentro y fuera del aula.

Sujeto 4: después que hace la prueba también conversa con ellos, en la conversación también diaria que se produce uno también les enseña cosas.

Sujeto 5: Sí, ellos, igual es parte porque yo he tratado de ser una persona lo más correcto posible para tratar de ser como un referente y, que igual tiene su precio, pero igual sus cosas de valor. El hecho de que mi comunidad me respete, me valore, me quiera, es porque me he preocupado de eso, de ser uno.

Sujeto 7: ¿En qué fundamentas los aspectos que tú apuntas a fortalecer, en el desarrollo espiritual de tus estudiantes?

O sea, de mi me nace por mi crianza, por cómo me criaron, lo que aprendí del colegio donde yo estuve, y lo que yo he visto en mi vida. He visto personas como todo el mundo, he visto personas que son buenas, personas que son malas, por qué hacen cosas malas, por qué hacen cosas buenas. Entonces yo pienso, pienso, pienso, pienso, y hago un compendio de eso y yo veo que aspectos buenos puedo sacar de eso y trato de comunicarlo a los niños, a los estudiantes.

Sujeto 2: Y no te digo yo que a todos los catequicé, y a todos los convertí, no, porque no era mi objetivo, el objetivo mío es la clase, cuando yo comienzo una clase y 
empiezo con la oración inicial, por ejemplo, en la mañana es, yo, darle gracias a dios porque estoy con ellos en clases, y si ellos quieren escuchar de que existe un dios, bien, si no, bien, y como te digo, los valores que enseño, la parte espiritual que enseño es cristiana.

\section{Discusión}

Al analizar los resultados obtenidos a partir de lo que los sujetos expresan, se detectan algunos puntos centrales en función de los propósitos de nuestro trabajo.

No deja de ser relevante que, transcurridos más de 45 años de la declaración de la UNESCO (Faure, et al.,1973), respecto a la sobrevaloración de las habilidades para el desarrollo tecnocientífico en los estudiantes, en desmedro de otras dimensiones importantes para la vida, los docentes elaboren críticas y teorías que siguen la misma línea argumentativa. La valoración positiva por parte de los docentes hacia la educación integral es concordante con la visión de la UNESCO y los autores citados en el marco teórico de este estudio. Valdría entonces la necesidad de revisar los esfuerzos de la sociedad chilena y su eficacia en materia de política educativa y de los medios que se necesitan para que estos no continúen siendo percibidos como letra muerta.

Los sujetos, además, ven en la educación integral un medio para mejorar la humanidad. Si bien, Delors, et al. (1996) y Sánchez Andrade y Pérez Padrón (2017), refieren constantemente al desarrollo de la persona en diversas dimensiones, se desprende de ello una meta del humanismo que, por lo tanto, involucra implícitamente el desarrollo de una humanidad mejor. Llama la atención que los sujetos sientan contradicciones tan importantes respecto a lo que perciben como el objetivo de la educación en Chile y lo que este finalmente debiese ser, lo que podría relacionarse con la falta de ocupación que perciben los sujetos para que aquello que se declara en las políticas educativas nacionales pueda, finalmente, concretarse en la búsqueda de construir una mejor sociedad. Resultaría de interés el indagar con mayor profundidad acerca de las razones que resultan en esta dificultad. Un posible punto de inicio se desprende de elaboraciones de los mismos sujetos y que versan sobre la falta de tiempo, la incompetencia de los altos cargos en políticas públicas y programas demasiado ambiciosos en cuanto objetivos de aprendizaje específicos de cada asignatura.

Otro aspecto de interés es la unánime valoración positiva que tienen los docentes de su trabajo para la educación integral y la educación espiritual como parte de ella. Si bien, en algunos los sujetos confundieron educación integral con educación inclusiva, cuando se abordaban explícitamente temáticas respecto a objetivos transversales o el desarrollo del ser humano en diversas áreas, los docentes cuyo dominio del concepto era escaso valoraban y elaboraban teorías de manera similar al resto. Más, sobre el concepto de educación espiritual, este se asocia principalmente al cultivo de valores o actitudes positivas y aun cuando los sujetos pudiesen asociarlo también a la religión, lo hacían en función de lo valórico y no de aspectos de significación de la realidad o la búsqueda del sentido como plantea por ejemplo Torralba Roselló (2016) y lo declarado en las bases curriculares (MINEDUC 2015b; 2018). Por lo tanto, una condición que se da transversalmente, en las 
entrevistas con los sujetos, es la equívoca cuasi homologación de la educación espiritual con la educación en valores.

Respecto a las iniciativas personales para trabajar la educación integral y las teorías que los sujetos construyen como medios para la educación espiritual, nuevamente recordamos a Faure, et al. (1973) y su advertencia sobre la infravaloración de la educación integral y cómo esto resulta en un trabajo anárquico cuando los docentes intentan hacer algo por ella. Las iniciativas de los docentes tienen como punto de partida la propia intuición o la experiencia personal que, por supuesto es diversa, resultando en un trabajo que, si bien es disperso en relación con los objetivos que planeta el MINEDUC, tiene puntos de encuentro en la interpretación que hacen los sujetos, como la valoración del diálogo y la educación a través del ejemplo.

Destacan positivamente las elaboraciones teóricas que refieren a la disociación de la educación espiritual de la religión. Los sujetos tienden a valorar la religión como un espacio que permite la búsqueda y el desarrollo valórico, más no le atribuyen exclusividad, siguiendo la actual línea académica del concepto (Rodríguez, 2013). Por lo mismo, finalmente ven la posibilidad de, con más o menos dificultades, trabajar la dimensión espiritual en todas las asignaturas, lo que se condice con lo declarado como objetivos de aprendizaje transversales en las bases curriculares (MINEDUC, 2015b; MINEDUC, 2018), más no hacen nunca mención de éstos cuando se trata particularmente de educación espiritual, evidenciando nuevamente una necesidad a cubrir.

Considerando todo lo anterior, los docentes elaboran teorías respecto al rol de la educación espiritual como elemento de valor para la orientación de los estudiantes, siendo la ocasión en que se trasciende, aunque de manera muy tímida, lo valórico hacia la significación de la propia vida, la convivencia y el entorno, acercándose al planteamiento de Gardner (1999) y los objetivos de aprendizaje transversales de las bases curriculares. Siendo este punto el de mayor acercamiento de los sujetos a lo que se entiende por educación para el desarrollo espiritual, queda manifiesta la poca preparación de los docentes, en materia de educación espiritual, junto a la falta de autocrítica respecto a la valoración de su trabajo para ello.

Cabe mencionar que, al finalizar la etapa de entrevistas, queda claro que los sujetos reflexionan sobre el concepto de educación espiritual de manera inicial a partir de este trabajo de investigación, incluso expresando sorpresa por la temática, por tanto, si bien elaboran teorías, lo hacen principalmente sobre la educación en valores como parte de la educación integral, más que sobre educación espiritual. En ello advertimos una primera posibilidad de ampliar este estudio, buscando las teorías que construyen los sujetos una vez asimilado el concepto de educación espiritual propiamente tal.

Por último, una construcción que llama la atención es la búsqueda de espacios de horizontalidad, en el trato con los estudiantes para trabajar el desarrollo espiritual, ante lo cual vale preguntarse ¿de qué manera visualizan los sujetos esta posibilidad en contextos escolares marcados tradicionalmente por la verticalidad jerárquica? ¿Qué es lo que los sujetos están entendiendo por horizontalidad? Esto sumado a que los mismos docentes han 
criticado sostenidamente la verticalidad a la que ellos están sujetos respecto a los equipos de gestión, a la vez que estos últimos se ven en la obligación de responder a las tradicionales mediciones externas. Vemos, en este aspecto, una segunda posibilidad de ampliar este estudio investigando las teorías subjetivas tanto de estudiantes como de equipos de gestión respecto al tema, buscando las relaciones que puedan o no haber con lo recogido en el presente trabajo.

\section{Conclusiones}

Los profesores entrevistados sostienen teorías subjetivas en torno a la educación integral y la educación espiritual como parte de esta en un nivel teórico restringido, siendo capaces de manifestar una estructura argumentativa coherente, pero sin mayor profundidad. Esto puede deberse al poco conocimiento sobre educación espiritual, que se evidencia en la homologación que hacen de esta con la educación en valores, y a la necesidad de reflexionar y construir sus teorías en el momento mismo de las entrevistas.

Valoran positivamente la educación espiritual y ven en ella un medio de impacto para la mejora tanto personal y social, asociado principalmente al desarrollo valórico y a la necesidad de orientación de los estudiantes. Sin embargo, no visualizan la posibilidad de trabajar sistemáticamente el desarrollo de esta dimensión de la persona, responsabilizando principalmente a las políticas educativas y en parte a los equipos de gestión. Esto no impide que los docentes por iniciativa particular concreten ciertas acciones que sienten pertinentes al tema, pero motivadas por teorías personales que suelen coincidir con lo que sostienen sus pares.

Se detecta que el alcance de las políticas educativas, sobre la educación para el desarrollo espiritual, no llega a formar parte del ideario educacional de los docentes. La crítica de estos ante la poca claridad sobre la espiritualidad que la sociedad persigue, y a falta de elementos curriculares para trabajar la educación espiritual, no es acompañada de una autocrítica respecto al conocimiento de las bases curriculares que, aunque de manera incipiente, ofrecen lineamientos en este aspecto, más bien lo es de teorías relacionadas con el rechazo a los altos cargos responsables de las políticas educativas y al poco interés por hacer efectivo las declaraciones sobre la educación integral. Pese a ello, destaca la valoración positiva de su trabajo para la integralidad y el desarrollo espiritual como parte de esta, a través de prácticas como el diálogo, la alta valoración del ejemplo y de la propia creencia como medio para educar en la dimensión espiritual.

Por último, si bien en su definición de educación espiritual se encuentran restringidos respecto a las orientaciones ministeriales, resaltando sólo lo valórico y dejando de lado cuestiones sobre el sentido, la finitud y la trascendencia del ser humano, en la elaboración de sus teorías coinciden en la valoración de esta dimensión y en la necesidad de desarrollarla para formar estudiantes que se sientan orientados en su vida personal y social. 


\section{Reconocimientos}

Este trabajo se presentó para optar al grado académico de Magister en Educación Inclusiva en la Universidad Central, bajo la guía de Carola Cerpa Reyes.

Todos los datos relacionados con la investigación (audios de las entrevistas y sus correspondientes transcripciones), están sujetos a un acuerdo de confidencialidad. El Editor General de Cuadernos de Teología-Universidad Católica del Norte, da fe de la existencia de aquellos. La herramienta metodológica pueda encontrarse en el anexo.

\section{Referencias Bibliográficas}

Álvarez Rodríguez, J. (2001). Teorías subjetivas de profesores de la Región de Coquimbo (Chile) sobre educación espiritual como parte de una educación integral (Tesis Doctoral). Universidad de Granada. Departamento de Métodos de Investigación y Diagnóstico en Educación, España. https://bit.ly/2U7r7vE

Beltrán Marín, A. (2018). La ecosofía como condición de posibilidad para una educación desde la sensibilidad ambiental. (Tesis de Magíster en Educación: Desarrollo Humano). Universidad de San Buenaventura, Facultad de Educación, Armenia, Colombia. https://bit.ly/35bKXMz

Benavent Vallés, E. (2014). Espiritualidad: heterodoxia y punto de encuentro, un activo para la educación social. Educació social (Internet), (56), 13-30. https://bit.ly/3eJdlsH

Boff, L. (1996). Ecología: grito de la Tierra, grito de los pobres (J. C. Rodríguez Herranz, Trad.). Madrid: Trotta.

Brighenti Bortoluzzi, M., y Catalán Ahumada, J. (2014). Teorías subjetivas de profesores en reuniones de trabajo: un estudio descriptivo-interpretativo. Psicologia escolar e educacional, 18(1), 151-159. https://doi.org/10.1590/s1413-85572014000100016

Canales Cerón, M. (2006). Metodologías de investigación social. Introducción a los oficios. Santiago de Chile: LOM.

Catalán Ahumada, J. (2010). Teorías subjetivas. Aspectos teóricos y prácticos. La Serena: Editorial Universidad de La Serena.

Catalán Ahumada, J. (2016). Hacia la formulación de una teoría general de las teorías subjetivas. Psicoperspectivas. individuo y sociedad, 15(1), 53-65. https://doi.org/10.5027/psicoperspectivas-Vol15-Issue1-fulltext-739

Conferencia Episcopal de Chile. (2020). Bases curriculares y programa de estudio asignatura religión católica. Santiago: Santillana. https://bit.ly/2lvvE8l

Creswell, J. W. (1994). Research design. qualitative \& quantitative approaches. Thousand Oaks, CA: Sage.

Cuñat Giménez, R. (2007). Aplicación de la teoría fundamentada (grounded theory) al estudio del proceso de creación de empresas. En Decisiones basadas en el conocimiento y en el papel social de la empresa: XX Congreso anual de AEDEM (Vol. 2, Art. ID. 44). España: AEDEM. https://bit.ly/2JN1GgN 
Cuesta Benjumea, C. (2006). La teoría fundamentada como herramienta de análisis. Cultura de los cuidados, 10(20), 136-140. https://doi.org/10.14198/cuid.2006.20.19

Delors, J., Al Mufti, I., Amagi, I., Carneiro, R., Chung, F., Geremeck, B., ... Nanzhao, Z. (1996). La educación encierra un tesoro: informe a la UNESCO de la Comisión Internacional sobre la educación para el siglo XXI. París: UNESCO. https://bit.ly/3klyryi

Faure, E., Herrera, F., Kaddoura, A. R., Lopes, H., Petrovski, A., Rahnema, M., y Ward, F. C. (1973). Aprender a ser: la educación del futuro (2a ed.) (C. Paredes de Castro, Trad.). Madrid: Alianza. https://bit.ly/36mbl5Q

Flick, U. (1991). Alltagswissen über gesundheit und krankheit. subjektive theorien und soziale repräsentationen. Heidelberg: Asanger.

Gardner, H. (1999). La inteligencia reformulada: las inteligencias múltiples en el siglo XXI. Barcelona: Paidós.

Gervilla Castillo, E. (2000). Un modelo axiológico de educación integral. Revista española de pedagogía, 58(215), 39-58. https://bit.ly/3kevmjv

Groeben, N. y Scheele, B. (1977). Argumente für eine psychologie des reflexiven subjekts. Steinkopff. https://doi.org/10.1007/978-3-642-85300-5

Ley № 20.370. Establece la Ley general de educación. Diario Oficial de la República de Chile, Santiago, Chile, 12 de septiembre de 2009. http://bcn.cl/2f73j

Ley No 20.845. De inclusión escolar que regula la admisión de los y las estudiantes, elimina el financiamiento compartido y prohíbe el lucro en establecimientos educacionales que reciben aportes del Estado. Diario Oficial de la República de Chile, Santiago, Chile, 08 de junio de 2015. http://bcn.cl/2f8t4

Meza Rueda, J. (2010). Ecosofía: otra manera de comprender y vivir la relación hombremundo. Cuestiones teológicas, 37(87), 119-144. https://bit.ly/3IIKPQm

Miles, M. y Huberman, A. (1994). Qualitative data analysis: a sourcebook of new methods. London. Sage.

Ministerio de Educación. (2013). Bases Curriculares Orientación $1^{\circ}$ a $6^{\circ}$. https://bit.ly/2JU5bCm

Ministerio de Educación. (2015). Orientaciones para la revisión y actualización del Proyecto Educativo Institucional. https://bit.ly/3ljhupE

Ministerio de Educación. (2015b). Bases Curriculares para 70 básico a $2^{\circ}$ medio. https://bit.ly/3kingXI

Ministerio de Educación. (2017). El primer gran debate de la reforma educacional: ley de Inclusión Escolar. https://bit.ly/3nbUMQU

Ministerio de Educación. (2018). Bases Curriculares primero a sexto básico. https://bit.ly/32uTqlZ

Organización de Naciones Unidas. (1948). Declaración Universal de Derechos Humanos. https://bit.ly/3k1LJAz 
Organización de las Naciones Unidas para la Educación, la Ciencia y la Cultura, (2016). Educación 2030: declaración de Incheon y marco de acción para la realización del objetivo de desarrollo sostenible 4: garantizar una educación inclusiva y equitativa de calidad y promover oportunidades de aprendizaje permanente para todos. https://bit.ly/32wnrrQ

Palacio Vargas, C. (2015). La espiritualidad como medio de desarrollo humano. Cuestiones teológicas 42(98), 459-481. https://bit.ly/38HAw5J

Páramo Morales, D. (2015). La teoría fundamentada (Grounded Theory), metodología cualitativa de investigación científica. Pensamiento \& Gestión, (39), 119-146. https://bit.ly/2lexafG

Rodríguez, T. (2013). Inteligencia espiritual. Sapiens, 14(1), 11-21. https://bit.ly/2UeQED2

Salgado Lévano, A. (2007). Investigación cualitativa: diseños, evaluación del rigor metodológico y retos. Liberabit, 13(13), 71-78. https://bit.ly/3elUsGh

Sánchez Andrade, V. y Pérez Padrón, M. (2017). La formación humanista. Un encargo para la educación. Universidad y Sociedad, 9(3), 265-269. https://bit.ly/2JPBwtP

Sfeir-Younis, A. (2009). Educación, economía ambiental y espiritualidad. Revista de estudios sociales, (32), 240-254. https://bit.ly/3eJBsHw

Taylor, S. J., y Bogdan, R. (1984). Introducción a los métodos cualitativos de investigación: la búsqueda de significados (J. Piatigorsky, Trad.). Barcelona: Paidós.

Toledo Manzur, V. (2013). El paradigma biocultural: crisis ecológica, modernidad y culturas tradicionales. Sociedad y Ambiente, 1(1), 50-60.

Torralba Roselló, F. (2010). Inteligencia espiritual. Barcelona: Plataforma.

Torralba Roselló, F. (2016). La inteligencia espiritual en los niños. Barcelona: Plataforma.

Villalobos, C. y Salazar, F. (2014). Proyectos educativos en el sistema escolar chileno: una aproximación a las libertades de enseñanza y elección. Informes para la política educativa, (2) 10 p. https://bit.ly/3ngteK9

Zohar, D., y Marshall, I. N. (2001). Inteligencia espiritual (M. Covián, Trad.). Barcelona: Plaza \& Janés. https://bit.ly/3pgwaYZ

\section{Para citar este artículo bajo Norma APA 7a ed.}

Díaz Ledezma, S y Gómez Loyola, S. (2020). Teorías subjetivas de profesores de la Región de Coquimbo (Chile) sobre educación espiritual como parte de una educación integral. Cuadernos de teología - Universidad Católica del Norte (En línea), 12, e4291, https://doi.org/10.22199/issn.0719-8175-2020-0004

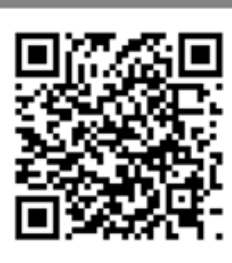

DOI

Copyright del articulo: @2020 Sebastián Díaz y Santiago Gómez

(cc) BY

Este es un artículo de acceso abierto, bajo licencia Creative Commons BY 4.0. 